\title{
EDITORIAL: PODER ASOCIATIVO
}

Con motivo de los veinticinco años de la Asociación Colombiana de Terapia Ocupacional, hacemos un llamado a fortalecer nuestro poder asociativo, representado en nuestra participación dinámica y comprometida con las actividades de la Asociación. No se trata de un tema novedoso. Por el contrario, todos los editoriales que se han producido en el tiempo de vigencia de la Revista Ocupación Humana (1984-1997) se relacionan, de manera directa o indirecta, con este asunto.

Sin embargo, en la actualidad el tema del poder asociativo cobra gran vigencia, por dos razones. Por una parte, se vive la época de la sociedad global donde el intercambio y las alianzas estratégicas son esenciales para el logro de propósitos individuales y empresariales de alta calidad e impacto. $Y$ por otra parte, el intercambio y establecimiento de alianzas es más efectivo cuando se cuenta con el respaldo de grupos y corporaciones claramente posicionadas en la sociedad.

En primer lugar, las condiciones de la sociedad global que vivimos hacen imperativo que los profesionales entiendan que ya no es vigente ni efectiva la actuación aislada, cerrada y circunscrita a un círculo limitado. Por el contrario, la productividad, el progreso y la posibilidad de influir en los grandes debates sociales requiere un estilo de vida abierto, competitivo, ingenioso y perceptivo de los múltiples convenios, redes y estrategias interindividuales $e$ interinstitucionales que pueden facilitar y agilizar el cumplimiento de las metas y asegurar resultados significativos para la persona y para la sociedad.

$Y$ estas estrategias y redes se empiezan a formar en los espacios de nuestro propio gremio; en el díalogo razonado que establezcamos con nuestros pares profesionales; en los aportes de calidad y avanzada que brindemos a nuestro grupo profesional y por esa vía a la Terapia Ocupacional y a la sociedad.

En segundo lugar, conviene no olvidar que son los grupos y corporaciones mejor posicionadas en la sociedad los que hacen posible las alianzas 
más exitosas y poderosas. El cumplimiento de metas es más efectivo cuando se cuenta con el respaldo de un grupo o corporación que tenga reconocida presencia social. O sea, la fortaleza de la Asociación de Terapia Ocupacional contribuirá a facilitar nuestros propios logros. Sin embargo, para que la Asociación sea fuerte requiere, ante todo, del amplio aporte de los Terapeutas Ocupacionales.

Los grupos ocupacionales que gozan de mayor prestigio y reconocimiento social son aquellos que tienen un alto perfil social, por cuanto cumplen las condiciones de profesión, descritas por los estudiosos de la sociología ocupacional. Una "profesión", por contraste con una "semiprofesión", se caracteriza por: un proceso de capacitación formal; un cuerpo de conocimientos reconocido por la comunidad científica amplia; autonomía en el ejercicio de sus funciones; estándares de ejercicio; un código de ética compartido por todos los representantes del grupo; y un ente asociativo que actúa como su representante ante la sociedad.

La Terapia Ocupacional en Colombia cumple algunas de estas condiciones y muestra debilidad de otras. Aunque este análisis debería ser materia de debates posteriores, aquí interesa resaltar que la fortaleza del grupo profesional es un requisito para que una ocupación califique como profesión. Al respecto, presumimos que una aspiración de todos los terapeutas ocupacionales colombianos es el creciente posicionamiento social de la Terapia Ocupacional.

La Asociación Colombiana de Terapia Ocupacional es y será lo que sus asociados decidan que ella sea. Son muchas las ventajas competitivas que representa para el futuro de cada uno de nosotros y de la Terapia Ocupacional contar con una asociación profesional de alta representatividad social. La estrategia más directa para lograrlo es incrementar nuestra presencia y productividad en la Asociación, de manera que impulsemos su desarrollo a niveles insospechados.

El concepto "sociedad civil" está de moda. Se dice que Colombia tiene una sociedad civil débil, lo cual ha traído múltiples consecuencias negativas. Nuestra forma más clara de contribuir al fortalecimiento de la sociedad civil en el país es dando vigor a nuestra agremiación, para que ella, con la fuerza que le dan sus asociados, actúe como interlocutor válido en los complejos debates contemporáneos en los que tenemos responsabili- 
dad de participar: "calidad, cobertura y oportunidad de políticas y programas relacionados con la ocupación en el contexto de la educación, la salud, el trabajo y la justicia social para todos los colombianos, en los niveles de promoción, prevención, tratamiento y rehabilitación".

Alicia Trujillo Rojas, M.A., OTR

Profesora Asociada

Universidad Nacional de Colombia

Santafé de Bogotá, Diciembre 5 de 1997. 